Supplement of Hydrol. Earth Syst. Sci., 21, 617-634, 2017

http://www.hydrol-earth-syst-sci.net/21/617/2017/

doi:10.5194/hess-21-617-2017-supplement

(C) Author(s) 2017. CC Attribution 3.0 License.

(c) (i)

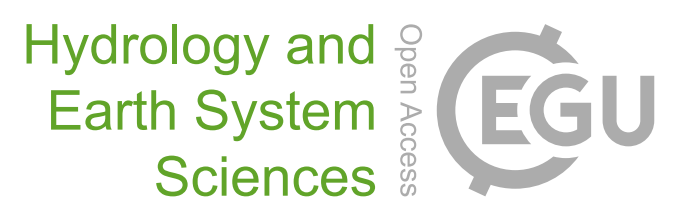

Supplement of

\title{
Gauge-adjusted rainfall estimates from commercial microwave links
}

Martin Fencl et al.

Correspondence to: Martin Fencl (martin.fencl@ fsv.cvut.cz)

The copyright of individual parts of the supplement might differ from the CC-BY 3.0 licence. 


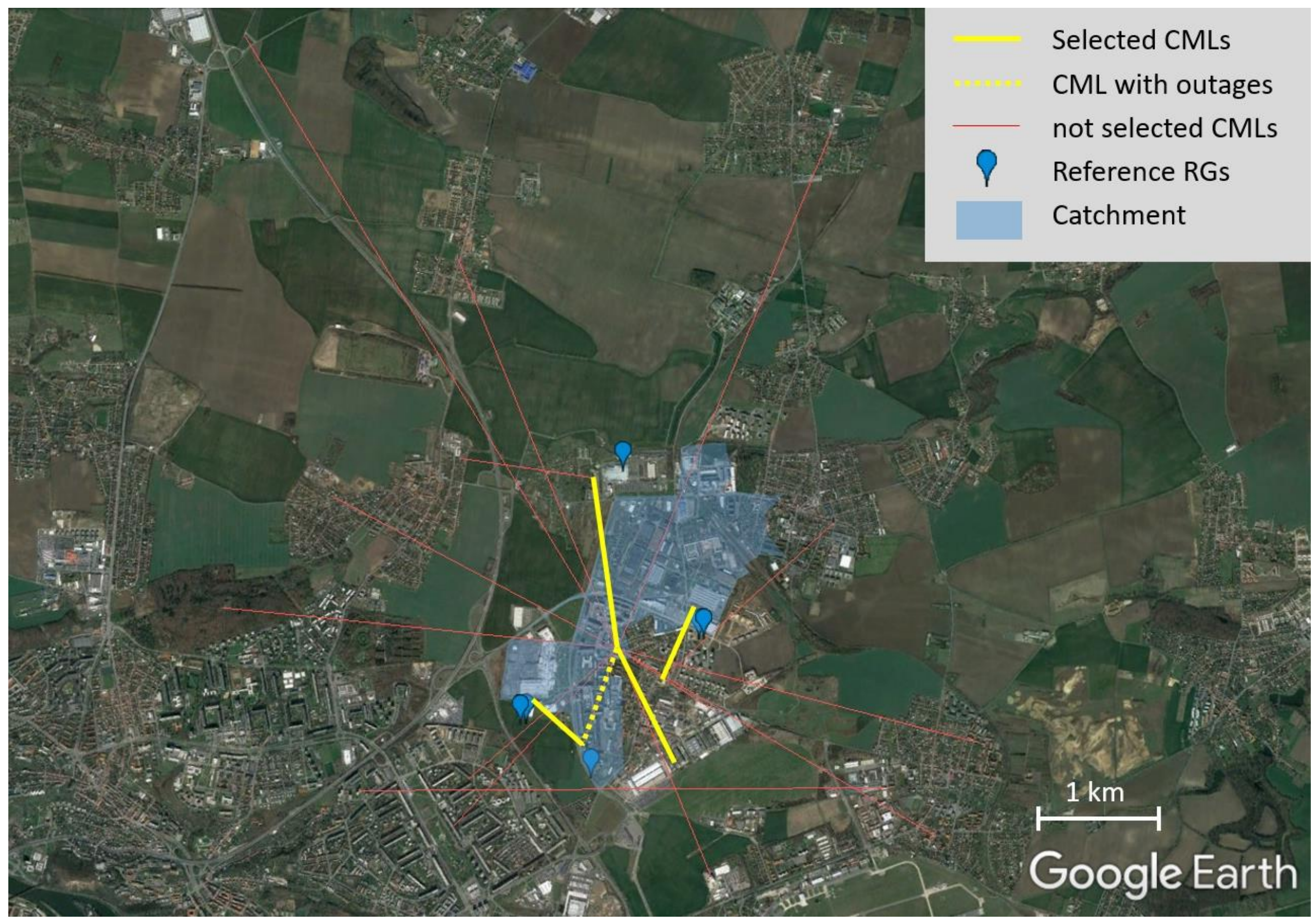

Detailed view on the network of commercial microwave links (CMLs) operated by T-Mobile (CZ) in the catchment Prague-Letnany together with reference rain gauges (RGs) operated for experimental purposes. Exact coordinates of CMLs are not provided due to confidential character of this information. 